\title{
Para uma teoria crítica do eurocentrismo: história, colonialismo e o resto do mundo
}

\author{
Pedro Borba
}

\section{Pedro Borba}

Mestre e Doutor em Ciência Política pelo Instituto de Estudos Sociais e Políticos da UERJ, onde está vinculado como pesquisador ao Núcleo de Estudo em Teoria Social e América Latina. Atualmente é Professor Colaborador da Universidade Estadual de Londrina e Professor-Tutor do Mestrado Interuniversitário em Estudos Contemporâneos da América Latina na Universidade Complutense de Madri.

E-mail: pedroborba.cp@gmail.com

ORCID: https://orcid.org/0000-0003-0045-3248

\section{Resumo}

Esse artigo pretende desenvolver uma crítica ao eurocentrismo como representação hegemônica de mundo, precisando os termos de um debate já em curso nas Ciências Sociais. Enquadra o eurocentrismo como categoria histórica a partir da diferença colonial, tendo a América como espaço privilegiado de análise. Em sequência, propõe a crítica ao eurocentrismo como um feixe entre perspectiva, contraposição e desvelamento. Assim, as perspectivas sobre a modernidade desde suas margens, a contraposição à universalização da experiência europeia e o desvelamento de novas fronteiras de conhecimento e pesquisa, ao se conjugarem, permitiriam levar a denúncia corrente a um plano reconstrutivo. Ao invés de uma saída ecumênica (baseada no pluralismo multicultural) ou paroquialista (baseada no rechaço unilateral ao cânone), o artigo defende a crítica ao eurocentrismo como movimento criativo, aberto pelo conflito com um monólogo histórico instituído reflexivamente pelo colonizador.

\section{Palavras-Chaves}

Eurocentrismo, Colonialismo, Teoria Crítica, América Latina.

\begin{abstract}
This paper intends to develop a critique of Eurocentrism as hegemonic representation of the world, sharpening the terms of an ongoing debate in Social Sciences. It frames Eurocentrism as an historical category based on colonial difference, using America as privileged site for analysis. Besides, the paper suggests a critical approach of Eurocentrism based on a beam of perspective, counter-position and discovery. Thus, the perspectives on modernity from its margins, the counter-position against the universalization of European experience and the unraveling of new frontiers of social research, as they mingle, would allow us to bring current complaint into a reconstructive ground. Instead of solutions of ecumenical (based on multicultural pluralism) or parochialist (based on unilateral denial of Western thought) features, the article sustains the critique of Eurocentrism as creative movement, opened by the conflict against an historical monologue reflexively instituted by the colonizer.
\end{abstract}

\section{Key-Words}

Eurocentrism, Colonialism, Critical Theory, Latin America. 
Pedro Borba

\section{Introdução}

Nas últimas quatro décadas, a discussão sobre eurocentrismo nas Ciências Sociais adquiriu notável ímpeto, a ponto de tornar-se quase inescapável entre os praticantes da área. Há um mal-estar generalizado com a universalização de um cânone intelectual restrito, mas sua superação não tem contornos claros nem uniformes (Amin, 1989; Bhambra, 2007, 2014; Chakrabarty, 2000; Chandra, 2013; Comaroff \& Comaroff, 2013; Connell, 2012; Knöbl, 2015; Lander, 2005; Quijano, 2000; Wallerstein, 1997; entre outros). Este ensaio pretende dois movimentos complementares a esse respeito: por um lado, recorrer à história para compreender o eurocentrismo no bojo do arco temporal do colonialismo moderno e suas representações de mundo; por outro, propor bases para uma teoria crítica dessa representação. Essas bases presumem a confluência de três movimentos: a crítica enquanto contraposição a uma situação estabelecida, a crítica enquanto ponto de vista subalterno e a crítica enquanto um desvelamento de conhecimento novo sobre a realidade.

Para nutrir o argumento, interessa observar a construção e a crise de um imaginário particular sobre a história, em que o protagonismo, a racionalidade e o progresso são alinhados ao poder colonial. A história universal pôde ser concebida na medida em que a diferença colonial $^{1}$ forneceu o gabarito para compreender povos e culturas, tornando-as comensuráveis, comparáveis ou, no limite, irrelevantes. É a partir da fissura desse imaginário, algo que é historicamente tangível, que o "antieurocentrismo" se torna um movimento inteligível, não como uma postura utópica transcendental, mas como um desenvolvimento imanente da própria realidade. A proposta, em síntese, é fazer da crítica não só uma oposição ao cânone intelectual estabelecido, mas como caminho de descoberta a partir de uma perspectiva periférica.

O texto elabora o ponto em quatro etapas afora esta introdução. Na primeira seção, um esclarecimento inicial sobre o conceito de eurocentrismo é apresentado como base para as etapas seguintes. Colocando o fenômeno em movimento, a segunda seção parte da experiência fundadora da diferença colonial nas Américas para examinar a produção de conhecimento enquanto instância do expansionismo europeu, culminando na formação de uma ciência histórica universalista e evolutiva no século XVIII. A terceira seção indica alguns parâmetros da obsolescência relativa dessa representação ao longo do século XX. Em um quarto momento, o artigo revisita o pensamento crítico em Ciências Sociais para subsidiar uma plataforma anti-eurocêntrica, detalhando o feixe estabelecido entre ponto de vista subalterno, contraposição política e desvelamento de realidade. A etapa final resgata a polêmica sobre o significado de "provincializar a Europa" a partir do que foi apresentado.

\section{Eurocentrismo como processo histórico}

Um primeiro passo é dissipar a confusão criada pelo uso indiscriminado do termo. Comecemos por um exercício rápido usando quatro significados possíveis e correntes: (1) diz-se que é eurocêntrica a supremacia de um cânone intelectual europeu ${ }^{1}$ moderno, transferido para currículos, citações e exames, em oposição a outras linhagens de pensamento que são vistas como necessariamente locais, específicas, empíricas ou datadas. Também diz-se eurocêntrica (2) a obsessão com o prestígio de universidades, institutos, editoras e periódicos dos países centrais, espaços privilegiados no campo que chancelam o conhecimento válido para o resto do mundo. Em outros contextos, o significado do termo está mais próximo de uma (3) 


\section{Pedro Borba}

extrapolação forçada por parte dos pesquisadores das experiências europeias à condição de conceito geral. Ou seja, o conteúdo de termos como democracia, guerra, classe operária ou nacionalismo está sobremaneira determinado pela experiência de algumas sociedades. Por fim, (4) a expectativa de que as instituições modernas (burocracia, capitalismo, laicidade, individualismo) se conformam no resto do mundo pela difusão instituciona/da história europeia é também sabidamente considerada eurocêntrica.

Um exame rápido demonstra que esses quatro significados são, digamos, ao mesmo tempo próximos e distantes. Obviamente próximos no sentido de que há relação intuitiva entre eles: instituições acadêmicas poderosas renovam certo cânone, que privilegia sua própria experiência histórica e, ao fazê-lo, restringe a ela a invenção institucional de todo o mundo em que vivemos. Se essas acepções parecem muito próximas para serem tratadas de forma separada, elas são distantes no sentido que indicam caminhos sutilmente diferentes para a superação do problema.

O questionamento do cânone teórico convencional (1) sugere o resgate do aporte de outras pensadoras e pensadores, provenientes de outros contextos, culturas e linguagens. A crítica à extrapolação forçada das experiências europeias (3), por sua vez, teria como contrapartida mais direta uma proposta de reavaliar os conceitos hegemônicos a partir de experiências periféricas, em si múltiplas e heterogêneas. Já a denúncia do establishment acadêmico internacional (2) aponta na direção de fomentar circuitos autônomos de produção e difusão de conhecimento no Sul Global. Por fim, crítica ao arcabouço difusionista das instituições modernas (4) traria ao primeiro plano a rediscussão acadêmica do excepcionalismo do "milagre europeu", isto é, da singularidade original que explicaria a supremacia europeia na história moderna. Em suma, embora sejam sentidos que aparentemente se tocam, eles não são necessariamente intercambiáveis.

O que há em comum nessas denúncias corriqueiras contra o eurocentrismo é a suposição de que ele representa uma distorção arbitrária do mundo não-europeu, da qual se poderia e deveria prescindir. Só deixaremos de repisar estereótipos se levarmos a sério as objeções desconfortáveis à denúncia, por exemplo: estudamos Marx ao redor do mundo por herança colonial ou porque ele de fato foi um notável crítico do capitalismo ao qual também estamos submetidos? Utiliza-se o termo nacionalismo fora da Europa pela força do eurocentrismo ou porque ali existem movimentos políticos propriamente nacionalistas? A centralidade hoje atribuída ao meio acadêmico estadunidense, francês ou inglês é resultado de nossa subserviência colonizada ou é consequência dos desproporcionais recursos que estes dispõem para fazer pesquisa e desenvolvimento, inclusive atraindo para seus departamentos os mais originais intelectuais das periferias?

A dificuldade de responder a essas perguntas de forma categórica é um contraponto necessário para transformar a denúncia de eurocentrismo em uma elaboração mais rigorosa sobre o mesmo. Como ponto de partida, reconhecemos que o eurocentrismo é parte constituinte do processo histórico de dominação europeia sobre o resto do mundo, que ao mesmo tempo se alimenta dessa dominação, busca entendê-la e concorre a legitimá-la (Abu-Lughod, 1989; Amin, 1989; Blaut, 1993; Dussel, 1992; Hall, 1995; Lander, 2005; Quijano, 2000). Nessa chave, não se trata de um vício acadêmico, mas uma representação socialmente hegemônica da realidade, em que a história de todo o resto do mundo é subsumida à narrativa de progresso do colonizador. A crítica a essa representação eurocêntrica, por sua vez, é inseparável de uma crise histórica, desdobrada ao longo do século XX, do mundo eurocentrado pelo colonialismo moderno, da qual contamos com um ponto de observação privilegiado no presente.

Sem essa relação básica, abriríamos largo terreno ao anacronismo na avaliação do passado, supondo o antieurocentrismo como uma postura moral abstrata. É através das 


\section{Pedro Borba}

resistências e impasses do colonialismo enquanto processo real que se pôde entrever, como possibilidade imanente, um mundo em que o próprio colonialismo não era intrínseco ou necessário. Não se pode perder de vista a relação, fartamente conhecida pela teoria crítica, entre os horizontes da política e os do conhecimento sobre ela. É nesse contexto que posicionamos o conceito de eurocentrismo como representação hegemônica de mundo.

\section{As representações de mundo do colonialismo}

Diego de Landa (1524-1579) foi um dos vários evangelizadores cristãos que percorreram o México nos primeiros anos da invasão espanhola. Franciscano nascido na província de Guadalajara, tornou-se conhecido pelas táticas draconianas de imposição da fé cristã em Yucatã entre 1549 e 1562, região à época marginal para a Coroa espanhola. Além da tortura e do encarceramento dos recalcitrantes, Landa executou uma incomparável destruição de livros, gravuras e registros da civilização maia. Como ele próprio rememora, "buscamos grande número de livros com estas suas letras, e porque não havia nada em que não houvesse superstição e falsidades do demônio, queimamo-los todos, o que muito sentiram e causou-lhes grande pesar" (Landa, 1959 [1566]: 105). Não obstante, a conversão dos índios ao cristianismo dependia, para Landa e vários outros contemporâneos, do conhecimento de sua língua, sua mitologia e de seus costumes por parte dos missionários. Na Espanha, Landa escreveria em 1566 uma "Relación de las cosas de Yucatán" sistematizando seu conhecimento acumulado na região com o intuito de facilitar o trabalho de seus sucessores. Desde sua redescoberta no século XIX, a Relación de Landa se tornou uma fonte indispensável para antropólogos e historiadores interessados em reconstituir a cultura maia à época da conquista, tal qual se tornou, para a cultura asteca, a Historia General de las cosas de Nueva España do franciscano espanhol Bernadino Sahagún (1499-1590).

O caso emblemático desse bispo que ao mesmo tempo destrói a memória e recria-a para dominá-la é particularmente eloquente do significado da colonização no campo do conhecimento. É-o não só no sentido mais óbvio, em que os invasores afirmam seu poder ao anular os símbolos da cultura conquistada, mas principalmente porque a própria ideia de uma narrativa histórica dos povos maias já não é possível sem remeter aos conquistadores. Igualmente, não é possível contar a história dos últimos cinco séculos dos guaranis, dos aztecas ou dos iroqueses na América sem fazê-lo frente, contra ou por meio da história da invasão ocidental. A recíproca desse raciocínio, contudo, é sistematicamente negada. A representação unilateral da conquista equivale à crença de que a história ocidental pode ser contada em sua própria evolução, sem depender para tal das narrativas dos povos subjugados, que são dispostos no mundo à espera do encontro colonial, no qual se diluem e subsomem.

Nesse sentido, a história eurocêntrica é antes de tudo um monólogo. Não se limita a atribuir aos europeus a faculdade exclusiva de constituir história, mas também confere ao colonizador a prerrogativa de despertar, deslanchar, iniciar a história do resto do mundo através da colonização. Em seus primeiros relatos americanos, Colombo caracteriza os habitantes nativos como "gente muito desprovida de tudo", isto é, não encontrava nada daquilo que lhe era familiar na Europa (Todorov, 1982: 44). Essa negação de reconhecimento tem consequências práticas: a anulação do que já é nada; a provisão de tudo o que falta: língua, hábitos, lei, produção, moral, artes e fé. O que está sendo disparado aqui é a estrutura assimétrica de representação que traduz o outro como contrapartida negativa, pela ausência que precisa ser suprida.

Nesse sentido, como experiência pioneira, a América se converte em um tubo de ensaio para a capacidade demiúrgica da dominação europeia, isto é, para a possibilidade do poder dos colonizadores fabricar uma sociedade colonial. Como diz Enrique Dussel, ao 


\section{Pedro Borba}

"des-cobrir" a existência das terras habitadas na América os europeus foram forçados "a 'abrir' o horizonte ontológico de compreensão do 'mundo da vida cotidiana' europeu a uma nova 'compreensão' da história como 'Acontecer Mundial', planetário" (Dussel, 1992: 35). Quando se está, por assim dizer, desprovido de tudo, urge absorver todos os aspecto da vida social ex nihilo; quando a história se resume a essa assimilação, então não há memória social a ser resgatada senão a da própria colonização.

Dessa forma, o monólogo em questão não se resume a um cacoete de desconsiderar o ponto de vista dos colonizados, como uma espécie de viés intelectual, porque essa negligência se baseia na destruição da transmissão física desse ponto de vista. A desaparição desses registros não é uma lacuna na história que possa ser plenamente reparada, mas é a própria história que existe para ser contada. Tal qual as catedrais que os espanhóis ergueram sobre os templos mesoamericanos demolidos, o relato de Landa passa a ser uma fonte primária em lugar dos livros que ele incendiou. Por essa percepção que Michel-Rolph Trouillot (1995), autor da primeira história da Revolução Haitiana em créole, sublinhou como o silenciamento do passado não se resume à escrita formal da história, mas se conforma muito antes na forma de constituição das fontes, da organização de arquivos documentais e na própria definição do que é a história que pode vir a ser narrada (Trouillot, 1995).

Quando Colombo desembarcou no Caribe e no México, além da incurável obsessão com o ouro, ele se ocupou em catalogar e nomear as plantas, frutos, animais, bem como informar a Coroa sobre as formas de comportamento e costumes dos nativos. É lógico, reforçando o ponto anterior, que essas designações são arbitrariamente superpostas àquelas já utilizadas. Mais do que plantas, as descrições dos viajantes vão costurando ao público europeu uma interpretação sobre um Novo Mundo. A partir das décadas de 1520 e 1530, combinam-se três fatores decisivos: a ampla circulação editorial de registros sobre a América, a conquista dos grandes impérios americanos (Inca e Azteca) e a formação da Escola de Salamanca ao redor de Francisco de Vitoria (Pagden, 1986: 57-64). Dali em diante, a Europa seria inundada de relatos de rituais mágicos, frutos alucinógenos, tribos canibais, animais extraordinários - tudo destilado pela pena inventiva de viajantes, clérigos, literatos ou funcionários reais. Entre a reiteração e a diferença, ocorre uma manipulação de símbolos e referências do mundo medieval, da exegese bíblica, da mitologia e dos estudos clássicos, inseparáveis de algum senso de novidade. Mas não se tratava simplesmente de fantasia; de Salamanca para o resto da Europa, a incógnita dos povos americanos constituiriam base para novas fronteiras de estudo filosófico (Meek, 1976).

Havia uma problemática de fundo: a adequação da cosmovisão da época à descoberta de povos culturalmente remotos e até então desconhecidos, vivendo em um continente separado daquele em que o deus cristão havia criado a humanidade. À primeira mão, havia uma hipótese inspirada no livro apócrifo de Esdras, segundo a qual os americanos descenderiam das dez tribos perdidos de Israel, ou a mitologia platônica da civilização perdida de Atlantis (Meek, 1976). O bispo jesuíta Juan Acosta, cuja "Historia natural y moral de las Indias" (1589) foi a obra mais lida sobre a América durante o século XVII, argumentava que a chegada de Cristo havia expulsado o demônio para um refúgio na América, onde cevara o culto à lua, ao sol, às estrelas - similares, a seu juízo, às idolatrias descritas no tempo de Moisés. Como mostrou Pagden (1986), ilustres pensadores europeus defendiam que os americanos descendiam ora dos fenícios (John Ogilby, 1600-1676), ora dos chineses (Johannes de Laet, 1581-1649), ora dos tártaros e trácios (Joseph-François Lafitau, 1681-1746), ou ainda dos antigos noruegueses (Hugo Grócio, 1583-1645).

Subjacente ao enigma americano estava o embrião de uma etnologia comparada. 0 teor do debate, para além da exegese bíblica, lidava com questões empíricas muito diretas: como poderiam os ameríndios serem as tribos perdidas de Israel se ali não havia traço de 


\section{Pedro Borba}

circuncisão, nem semelhança nas leis abraâmicas ou na língua falada? Seria a parecença de traços físicos relacionada à sua descendência oriental? Havia semelhança entre os pergaminhos encontrados na América Central e a escrita cuneiforme fenícia? Ou a melhor pista seria certos rituais descritos pelos viajantes, como a celebração canibal do inimigo derrotado, para aproximar os americanos dos relatos romanos sobre o barbarismo dos cítios? Para dirimir a questão, um valor crescente é atribuído à observação, à experiência, aos critérios empíricos de validação do conhecimento.

O colonialismo na América revolveu essa controvérsia intelectual que, reflexivamente, interpelava a própria sociedade europeia da época. Em suas mais diferentes acepções, o imaginário do ameríndio em estado natural constitui um contraponto, positivo ou negativo conforme a circunstância, ao povo que o subjuga. Um intelectual bastante excêntrico entre seus contemporâneos, como foi Michel de Montaigne (1533-1592), comenta em seus Ensaios que a América "era "um mundo na infância e o submetemos ao açoite e a uma dura escravidão", não por uma superioridade na justiça ou virtude. Em seguida, ao referir à conquista, afirma que "nós nos servimos da ignorância e da inexperiência deles para dobrá-los mais facilmente à traição, à luxúria, à avareza, e a todo tipo de desumanidade e de crueldade, seguindo o exemplo e modelo de nossos costumes" (Montaigne, 1972 [1588]: 417).

Há mais em jogo do que a denúncia do "exemplo e modelo de nossos costumes". Ao secularizar o Éden, a América construída pelos colonizadores - esse híbrido de paraíso perdido, selvageria imoral e inocência infantil - estabelece uma intuição contrafactual para reavaliar as instituições vigentes na Europa (Hall, 1995). É por esse contrafactual negativo que se elabora uma auto-imagem da civilização, do comércio, do pacto social, da indústria e das artes. Frente a um outro "muito desprovido de tudo", como Colombo descreveu à Coroa os nativos, a sociedade como um todo se torna um artifício humano, uma obra da razão, a decantação de um desenvolvimento prévio e acumulado. A mitologia do selvagem originário e do estado de natureza, que subsidia o racionalismo jusnaturalista dos séculos XVII e XVIII, é uma imaginação filosófica assentada sobre o monólogo da subordinação colonial. Um ícone dessa mitologia é a relação entre Robinson Crusoé e seu servo Sexta-Feira, do romance de 1719 de Daniel Defoe: o primeiro encarna o engenho humano e seu poder transformativo do indivíduo diligente, enquanto o nativo se mistura à dócil natureza a ser civilizada, polida, policiada. Se o colonialismo moderno produz uma representação hegemônica de mundo, ela repousa não só sobre a alteridade exótica dos povos selvagens ou orientais, mas fundamentalmente em torno da imagem por eles refletida, a humanidade, civilização ou raça encarnada pelos colonialistas.

Por fim, há um deslizamento decisivo nessa imaginação filosófica, que vai desgarrando-a definitivamente do universo da teologia e conectando-a à análise social como a conhecemos hoje. Trata-se da temporalização da diferença, que resolve a incógnita americana através de um estágio primitivo do qual os europeus se descolaram historicamente. Em outras palavras, mais do que bárbaros ou escravos naturais, os ameríndios seriam no presente o que os europeus também foram no passado, seriam eles testemunhos vivos da origem da humanidade como um todo, de sua forma primordial secularizada (Meek, 1976; Pagden, 1986). De alguma maneira, essa temporalização da diferença já fora sinalizada pela Escolástica espanhola do século XVI, aparece implícita na alusão de Montaigne ao "mundo na infância" ou na famosa expressão de John Locke, segundo o qual "no início, toda a terra era uma América" (Locke, 1994 [1689]: 111; ver também Hall, 1995: 509-514; Meek, 1976). No entanto, essa temporalização só adquiriria sua forma acabada no bojo de uma ressignificação da história que se desenvolve no século XVIII.

Essa nova filosofia da história, fortemente associada ao Iluminismo, tinha três aspectos básicos: a singularidade, a universalidade e a progressividade. A singularidade da história se refere à possibilidade de imaginar o transcurso do tempo como algo coerente em si, 


\section{Pedro Borba}

separado das inúmeras circunstâncias que especificavam as narrativas dos cronistas. Em lugar de uma história da Guerra do Peloponeso ou da República Romana, em si múltiplas, erige-se a História como fenômeno singular e abrangente. A condição para tal é a universalização: o sujeito da história é a humanidade como um todo, ou seja, existe um arco histórico que diz respeito à "totalidade da dimensão temporal da própria existência humana" (Jasmin, 2011: 379). Em terceiro lugar, essa totalidade se apresenta em uma evolução imanente de suas formas primordiais através de estágios de desenvolvimento. Esse caráter progressivo concebe, então, "o tempo histórico como uma medida da distância cultural (ao menos em desenvolvimento institucional) que se supunha existir entre o Ocidente e o não-Ocidente" (Chakrabarty, 2000: 07).

A civilização se conforma, assim, como um conceito temporalizado. Vindo do latim ao francês, o verbo civiliser equivale ao ato de polir, lapidar, aprimorar o objeto às suas formas mais perfeitas. A perfectibilidade do ser humano é um tema por excelência do Iluminismo europeu, um devir associado ao usufruto da razão. A civilização europeia não somente está na ponta de lança da história universal, mas é capaz de decifrar o outro a partir de seu passado, dos estágios mais rudimentares de seu próprio desenvolvimento. Como argumenta Ronald Meek (1976), essa secularização desemboca em uma teoria geral dos estágios da evolução material das sociedades humanas, da (1) caça e coleta, ao (2) pastoreio, à (3) agricultura e, por fim, (4) o comércio, patamar alcançado somente pelos próprios europeus. Enquanto gabarito que permite identificar e comparar quaisquer sociedades a partir de critérios empíricos, essa teoria sinalizaria a emergência do que conhecemos como ciências sociais, desgarradas da filosofia social e da teologia (Meek, 1976). A temporalização da diferença colonial já não se basta com a simples inferiorização do outro, porque primitivo ou infantil, mas subsidia "uma teoria da história universal e, a partir dela, um projeto político mundial" (Amin, 1989: 75).

O eurocentrismo é, assim sendo, uma representação de mundo do colonizador, construída reflexivamente sobre suas capacidades e experiências (Blaut, 1993). Conseguimos distinguir, recorrendo à construção da diferença colonial nas Américas, três movimentos pelos quais essa representação se torna possível. O primeiro diz respeito ao silenciamento como espoliação simbólica, como subsunção histórica resultante da conquista, que estabelece uma assimetria real, concreta, política. A diferença colonial é resolvida, nesse aspecto, em chave negativa. O segundo movimento, por outro lado, é criativo: uma contrapartida de efervescência cultural, científica, filosófica, que abre fronteiras ao conhecimento europeu. O poder imperial permite avanços efetivos no conhecimento sobre o mundo, enquanto o mundo a ser conhecido é cada vez mais talhado por esse poder de colonizá-lo.

O colonialismo se apresenta, assim, como fermento de inovação cultural, e é nesse contexto que a filosofia moral se desdobra em estudo comparado sobre as sociedades. Como vimos, reconhecer os ameríndios como humanos colocava a diferença colonial em outro plano de investigação. Como explicar o caráter das sociedades europeias da época diante da tabula rasa dos selvagens americanos, ou ainda, o que permite entender o poder de uns sobre os outros? Lidos na Europa, os relatos sobre a América seriam um dos insumos que poderiam "revelar algo sobre as características universais da cultura humana" (Pagden, 1986: 202). É esse movimento de inovação cultural que lança as bases do universalismo que hoje qualificamos como eurocêntrico.

O terceiro movimento é uma síntese dos dois anteriores por meio da temporalização da diferença. O monólogo histórico já não se limita ao épico protagonizado pelos conquistadores, mas alcança uma história universal da evolução da humanidade, de seu desenvolvimento imanente e progressivo. A experiência dos povos subjugados, antes destituída de mérito próprio, é reassimilada em uma narrativa de estágios sociais: o discurso histórico integra suas particularidades culturais em um movimento direcional. Ao identificar na própria sociedade 


\section{Pedro Borba}

europeia o estágio mais desenvolvido da história, como o dínamo que a movimenta para frente, esse quadro também coloca os europeus no único ponto de observação possível para decifrar plenamente esse desenvolvimento. 0 universalismo filosófico se transpõe à imaginação histórica, abrindo um leque de codificações temporalizadas da diferença (atraso, primitivo, tradicional, subdesenvolvido, pré-capitalista). Enquanto representação hegemônica de mundo, o eurocentrismo articula a facticidade do poder colonial, a imaginação do tempo histórico e uma forma específica de privilégio epistêmico. Em resumo, trata-se de uma reflexividade imperial que só se tornou possível e inteligível a partir do processo histórico de construção dos impérios ocidentais.

\section{Outros mundos possíveis}

Uma representação de mundo não sucumbe como uma fortaleza sitiada. Datar processos dessa natureza é sempre tarefa dúbia. Por um lado, é inegável que resistências ao projeto colonial são tão antigas quanto o próprio, e há diversidade considerável entre suas expressões ao redor do mundo. A designação anterior da história eurocêntrica como um monólogo não significa simplesmente que conflitos não tenha havido, mas que o significado dessas resistências e barganhas pôde ser absorvido, com sucesso apreciável, aos termos da narrativa de progresso do colonialismo moderno. Nela, as lutas anticoloniais se tornam obstáculos irracionalistas, exóticos e particulares ao curso da história universal. Metaforicamente, admitir que uma corrida tem obstáculos não é o mesmo que buscar compreendê-la a partir desses obstáculos.

De outra parte, a constituição de um polo contraditório no campo intelectual tampouco é em si um sinal da erosão histórica do eurocentrismo. A rigor, como apontou Wallerstein, "a história do moderno sistema-mundo também envolveu um contínuo debate intelectual sobre a moralidade do próprio sistema (Wallerstein, 2006: 02). Seria absurdo supor que os contemporâneos fossem indiferentes às práticas opressivas desencadeadas no resto do mundo sob o primado da diferença colonial, ou ainda que o pensamento moderno se resumisse à propaganda colonialista. Já no século XVI, o contraponto de Bartolomeu de las Casas ao trato espanhol dos ameríndios, e o debate teológico-político do qual fez parte, é um exemplo imediato do "debate intelectual" a que Wallerstein se refere. Outro caso célebre é a oposição do filósofo anglo-irlandês Edmund Burke às práticas do governo-geral inglês na Índia em fins do século XVIII (Chatterjee, 2011: 4-6). Por ocasião do julgamento do ex-governador Hastings no Parlamento Britânico, Burke o acusaria de guiar-se por uma "moralidade geográfica", segundo a qual as boas leis e normas morais viriam a ser modificadas em função de latitudes e climas (isto é, valeriam na metrópole enquanto eram suspensas na Índia). Alguns anos mais tarde, o intelectual mexicano Carlos María de Bustamante, militante ativo pela independência, observaria o mesmo paradoxo do liberalismo inglês como empreendimento imperial: "Que contradição! Pregar a liberdade no Tâmisa para sistematizar a escravidão no Ganges!" (Bustamante apud Quijada, 2003: 308).

Em suma, a operação da diferença colonial nunca foi um segredo aos contemporâneos, e as críticas aos métodos de construção imperial não são uma invenção recente do pós-colonialismo. Enquanto tal, isso não nos posiciona historicamente a erosão do eurocentrismo como representação de mundo. O que demarca uma inflexão histórica é quando a contestação anti-imperialista e a crítica ético-política ao universalismo europeu estão combinadas, e assim se reforçam mutuamente como contrapontos às margens do sistema mundial. Posicionar essa inflexão significa, ao mesmo tempo, identificar o processo de declínio relativo do império como forma política. É porque a dominação ocidental sobre o mundo se torna objeto de amplo dissenso que a cultura ocidental se torna menos plausível como universal; em outros termos, é porque a autodeterminação se coloca como "aspiração de uma 


\section{Pedro Borba}

época", e o governo imperial, como anacronismo, que são postas em questão as premissas culturais, raciais e científicas da supremacia ocidental sobre o mundo.

$O$ arco temporal dessa mudança é fundamentalmente o século XX. Em seu núcleo, estão os movimentos nacionalistas e anti-imperialistas na Ásia, África e América Latina, bem como as ligações entre eles que semeariam o "Terceiro Mundo". Há inúmeros episódios importantes para situar essa inflexão, como a guerra europeia de 1914 e a revolução soviética de 1917. Concorrem igualmente processos mais graduais, como a emergência da primeira potência industrial/militar fora do Ocidente, o Japão. Por seu próprio caráter, o processo pelo qual a hegemonia ocidental erodiu haveria de ser multicêntrico em suas origens e direções. No restante da seção, observaremos algumas matizes dessa crise.

A repercussão mundial da experiência da guerra total entre 1914 e 1918 foi um acicate para a descompactação entre Ocidente e razão, entre colonialismo e progresso. Como descreveu Michael Adas (1990), a guerra industrial na Europa pôs em xeque a presunção, longamente estabelecida, de que a tecnologia, as armas e a indústria seriam medida de uma superioridade civilizacional. A tecnologia ocidental deixava de ser um sinal inconteste de sua liderança no aprimoramento universal do gênero humano; com isso, balançava também a "convicção de que [os europeus] eram o mais racional dos seres, no controle de si, dos outros povos e de toda a criação" (Adas, 1990: 372).

Duas saídas se apresentaram a esse impasse, ambas com consequências para a autodeterminação dos povos não-ocidentais. A primeira delas foi a desvalorização do materialismo em nome de aspirações mais elevadas do espírito. Na América Latina, o primeiro movimento intelectual de construção de uma identidade comum foi impulsionado pelo Ariel (1900) de Rodó, que revalorizava a América hispânica por seus valores humanistas em oposição ao utilitarismo materialista da América anglo-saxônica. O desenvolvimento material inferior não era, por si só, impeditivo para uma missão civilizadora original. O nascimento de uma "raça cósmica", que aparece na leitura de Vasconcelos sobre o México pós-revolucionário, é herdeira dessa nova missão civilizadora, como outras muitas houve nos anos 1920 e 1930 (Funes, 2006). É nesse contexto que ganha corpo, com nuances próprias a cada contexto nacional, um movimento de redescoberta simbólica e política do substrato popular e não-europeu das sociedades latino-americanas, já não como deformação ou atraso, mas como força vital de uma singularidade nacional ainda por completar-se.

O motivo espiritualista de declínio do Ocidente se fez mais forte e claro com relação às civilizações da Índia e China, com repercussão nas artes, na filosofia e nas ideologias políticas. Já em fins de século XIX, o guru bengalês Swami Vivekananda atingiu enorme repercussão internacional ao resgatar em chave positiva a essência espiritual do hinduísmo em contraste com o desencantamento do mundo alcançado no Ocidente. Tal qual o arielismo na América Latina, os ensinamentos de Vivekananda tiveram também impacto na juventude indiana, proporcionando um senso de orgulho e de propósito. O tema ganharia ainda mais força no pós-guerra : o polímata bengalês Rabindranath Tagore, que recebeu o prêmio Nobel de literatura em 1913, consagraria de inúmeras formas esse desprezo pelo maquinismo disciplinar da sociedade ocidental, em si monótona, realista, uniforme, empirista. Em lugar de importar instituições políticas e econômicas, Tagore aspirava a uma sociedade orientada pelo senso de cooperação, amor e autoexpressão (samaj), cujo conteúdo espiritual e social não poderia senão ser indiano em seu cerne (Chakrabarty, 2000: 149-179; Chatterjee, 2011: 94-126). Como argumentou Chatterjee (1993), a primeira geração do movimento nacionalista indiano se orientou pela demarcação de uma vida interior livre do colonizador, em uma província espiritual e cultural que resistia ao domínio exterior, da burocracia e da técnica da administração colonial. A luta pela autodeterminação política seria, nesse sentido, um desdobramento da soberania realizada nesse âmbito introspectivo, familiar e religioso onde a nação se afirmara livre. 


\section{Pedro Borba}

Além desse giro espiritualista, que relativizava o universalismo do Ocidente como civilização, o segundo caminho para o impasse do pós-guerra olhava para as consequências da apropriação não-ocidental da indústria, da técnica e da burocracia. O Japão foi certamente a ponta de lança dessa apropriação, e a vitória militar em 1905 sobre a Rússia, uma potência do mundo branco europeu, invertia o sinal do determinismo racial oitocentista. A experiência japonesa de apropriação da modernidade, sem abdicar das raízes asiáticas, seria formativa para o nacionalismo chinês, incubado na virada do século por elites intelectuais exiladas em Tóquio (Karl, 1998). Com isso, era urgente repensar a Ásia para além do imperialismo ocidental, de modo a organizá-la politicamente contra ele. A história do século XX deixa claro que esse horizonte político não esteve cerrado na Ásia, mas foi um dos motes do terceiro-mundismo. A superioridade industrial e militar - com a qual os europeus haviam erigido impérios multicontinentais - não era uma prova da supremacia intrínseca, natural ou necessária destes, mas antes uma circunstância, um predicado passível de mudança. Da mesma forma, haveria de ser contingente a narrativa da "história universal" aduzida unicamente do desenvolvimento singular das sociedades europeias.

Para ilustrar essa dissociação entre imperialismo e progresso universal, vale mencionar o discurso de Haile Selassie, imperador da Etiópia, na Liga das Nações em junho de 1936. O reino da Etiópia havia sido admitido em 1923 na organização internacional, que aspirava restaurar o primado da diplomacia sobre o uso indiscriminado da força militar. Em outubro de 1935, contudo, o país foi invadido pela Itália fascista, cuja força aérea nos meses seguintes lançou gás mostarda contra a população civil. Selassie conseguiu fugir do país e alcançar Genebra, onde denunciaria a complacência das grandes potências com os crimes fascistas. No começo do discurso, ele ressalva que nunca deixou de "usar todos os meus esforços para trazer ao meu país os benefícios da civilização" (Selassie, 2011: 48). De fato, a agressão italiana ofendia a "conciliação e a arbitragem em que as nações civilizadas basearam a ordem internacional", e Selassie imputava responsabilidade às "cinquenta e duas nações que declararam culpado o governo romano" e nada fizeram a respeito. A corrupção da "moral internacional" ao jogo de conveniências dos estados europeus estabelece a ordem da força: enquanto Selassie institui a Etiópia no campo da civilização, da razão e do direito, ao imperialismo ocidental resta a violência arbitrária. A despeito do quanto possa prevalecer por esse meio, qualquer conteúdo civilizador resta irremediavelmente esvaziado.

O raciocínio de Selassie antecipa o núcleo d’O discurso sobre o colonialimo de Aimé Césaire, um dos textos políticos mais potentes do século XX. Em 1950, quando foi originalmente publicado, a libertação nacional afroasiática já era um processo em andamento, tanto uma agenda política internacional como um horizonte histórico de expectativas. É simplesmente abusivo e arbitrário, resume Césaire (1978), que uma civilização decadente sustente a prerrogativa de governar e civilizar outros povos. O nazismo, como ápice da bárbarie, havia revelado não a antípoda da cultura ocidental, mas sua brutalidade intestina que até então só se manifestara cruamente nas colônias. "Antes de serem suas vítimas, foram os cúmplices; que o toleraram, esse mesmo nazismo, antes de o sofrer, absolveram-no, fecharam-Ihe os olhos, legitimaram-no, porque até aí só tinha aplicado a povos não europeus" (Césaire, 1978: 18). Os colonizados conheciam nitidamente a bárbarie e a hipocrisia subjacentes ao progresso do colonizador; precisamente por isso, sua autodeterminação política é necessária, não como retorno ao passado mas como conquista do futuro: "é o colonizado que quer avançar e é o colonizador que o retém" (Césaire, 1978: 29).

A pespectiva da emancipação intelectual e psíquica das estruturas coloniais como constituinte da libertação política floresceria na geração de Guerreiro Ramos (1915-1982), Paulo Freire (1921-1997), Jules Nyerere (1922-1999), Ranajit Guha (1923-), Anouar Abdel-Malek (1924-2012), Frantz Fanon (1925-1961), Orlando Fals Borda (1925-2008) e 


\section{Pedro Borba}

Hussein Alatas (1928-2007). O arco temporal dessa "geração de Bandung" é o recorte que melhor ilumina as mudanças históricas através das quais a crítica ao eurocentrismo se tornou inteligível. Embora com apenas alguns pontos de observação, pudemos constatar como a representação de mundo forjada pelo colonialismo moderno sofreu fraturas sucessivas ao longo do século XX. É interessante pensar, assim, o anti-imperialismo não só como movimento político, mas como uma imaginação histórica alternativa. Como afirmou Nicos Poulantzas, "as reivindicações de autonomia nacional e de estado próprio da era moderna significam, na historicidade capitalista, reivindicações de uma história própria" (Poulantzas, 1979: 135). Se o privilégio epistêmico da inteligência europeia havia sido sua capacidade de definir e classificar o mundo em seus próprios termos, unificando a história mundial atrás de si, a insurgência anticolonial, para tornar possível sua agência na história, precisa recontá-la. A emergência política dos "povos sem história" traz à tona o problema da alteridade e da diferença, que já não poderia ser resolvido no âmbito do monólogo histórico herdado da colonização.

\section{Teoria crítica no resto do mundo: perspectiva, contraposição e desvelamento}

Nesta seção, tomamos a teoria crítica em um sentido deliberadamente amplo, sem equipará-la necessariamente à Escola de Frankfurt e suas derivações imediatas (Domingues, 2011). A intenção primeira é compreender o que caracteriza genericamente a teoria como crítica para que o anti-eurocentrismo seja pensado como um movimento dentro dela. Em um artigo célebre, Nancy Fraser recorre a uma formulação de Marx de 1843, em que a teoria crítica constitui uma "auto-clarificação das lutas e aspirações de uma época", de modo a defender que tais movimentos políticos sejam a referência com que se discuta, desenvolva e aprofunde a teoria (Fraser, 1985: 97-98).

José Maurício Domingues bem aponta o risco de tornar essa referência demasiado concreta e imediata. A localização da teoria crítica por ele proposta a coloca como um campo de questionamento da modernidade que não só se põe em oposição às instituições vigentes, mas que aspira, ao fazê-lo, discernir no presente as tendências e agentes que abririam caminho à "emancipação prometida anteriormente pela modernidade" (Domingues, 2011: 72). Nesse sentido, a teoria crítica se diferenciaria da ciência tradicional por pressupor a irredutibilidade da realidade ao existente: "a análise crítica do que existe assenta no pressuposto de que a existência não esgota as possibilidades da existência e que, portanto, há alternativas suscetíveis de superar o que é criticável no que existe" (Santos, 1999: 197).

A reabertura desse debate emerge, com efeito, da urgência em responder aos impasses do marxismo clássico como viga-mestra da superação imanente da modernidade, isto é, como "teoria do conhecimento da vontade revolucionária" (Lechner, 2012: 248). Diante deles, seria ingênuo supor que a crítica ao eurocentrismo resumiria todas as formas de desumanização e opressão desencadeadas pela modernidade. No entanto, como dissemos ao princípio, tratá-lo como um desvio meramente intelectual ou acadêmico tende a esfumar o quadro que esboçamos até aqui, em que o eurocentrismo é entendido como uma forma histórica de reflexividade imperial. $O$ argumento que se segue redescreve a teoria crítica como um feixe histórico entre contraposição, perspectiva e desvelamento. Antes de detalhar o significado de cada termo, vejamos um exemplo ilustrativo.

Publicado em 2004, o livro "Calibã e a Bruxa: mulheres, corpo e acumulação primitiva" de Silvia Federici oxigenou o debate marxista sobre a transição do feudalismo para o capitalismo, quando este já parecia obsoleto e reiterativo. Valendo-se de uma perspectiva de gênero, sua análise alça ao primeiro plano a emergência de uma nova divisão sexual de trabalho, em que o assalariamento masculino constituía base para o patriarcado. A subtração do controle das mulheres sobre seus corpos, sobre seu trabalho e sobre a reprodução humana 


\section{Pedro Borba}

se converte em chave para decifrar a ordem social emergente, assim como a "caça às bruxas", em um mecanismo de sufocamento de resistências a ela. Para a autora, reavaliar a posição das mulheres nessa história "significa não somente uma história oculta que necessita se fazer visível, mas também uma forma particular de exploração e, portanto, uma perspectiva especial a partir da qual se deve reconsiderar a história das relações capitalistas (Federici, 2004: 17). Nessa forma de postular o argumento, Federici reivindica três instâncias interligadas: o ponto de vista das mulheres sobre um processo que as reifica (perspectiva), a descoberta da imbricação entre acumulação primitiva e hierarquia sexual (desvelamento) e o antagonismo diante da opressão das mulheres e das narrativas que as tornam invisível, irrelevante ou espontânea (contraposição).

Sobre esse exemplo, há ainda três comentários pertinentes a fazer. Em primeiro lugar, é evidente que no argumento de Federici (2004) se entrelaçam diferentes movimentos de crítica que a precederam. Sua leitura sobre o surgimento do capitalismo é tributária tanto da crítica marxiana da economia política quanto da releitura crítica sobre o papel da escravidão e do colonialismo para a formação de um mercado de trabalho assalariado na Europa. Há efetivamente uma apropriação delas sob uma perspectiva feminista. A teoria crítica, assim, não é um artefato definitivo, nem se encerra no singular; ela antes desdobra-se em movimentos criativos sobre suas potencialidades. Como fazer histórico, a teoria crítica é sempre um espaço em aberto tanto quanto uma abertura de espaços.

Em segundo lugar, a preocupação da autora com a autonomia das mulheres no trabalho produtivo e reprodutivo não é uma volição utópica ou pessoal, mas é constituída a partir da disputa histórica e das resistências concretas ao ideal moderno da feminilidade. Por outro lado, essa ligação com as lutas não necessariamente equipara o horizonte emancipatório da política ao daquelas mulheres que foram supliciadas como bruxas no século XVI e XVII, ou às populações periféricas que estão hoje sendo alvo de políticas análogas à caça às bruxas. Sua dimensão política não resulta da transposição direta das perspectivas sobre as quais ela produz teoria.

Em terceiro lugar, o exemplo de uma obra e sua autora não pode nos levar à literalidade de individualizar seu significado. Enquanto desvelamento de realidade sobre a posição das mulheres na acumulação primitiva, a obra de Federici não é obviamente um raio em céu azul, mas é mencionada enquanto um ponto de captura para um processo coletivo e cumulativo de descoberta. O mesmo vale para a perspectiva de observação do processo. Seria equivocado reduzi-la à autoria de uma mulher individual. Sob pena de dizer o óbvio, vale lembrar que a condição de mulher enquanto perspectiva crítica sobre a realidade é uma construção histórica. Assim como o poder de desvelamento da obra não é resultado imediato da sapiência individual da autora, sua perspectiva crítica não se reduz ao fato de ela ser mulher. Nesse sentido, cabe apontar que a teoria crítica, além de plural em suas possibilidades, é coletiva e histórica como processo.

É nesse terreno que se posiciona uma teoria crítica do eurocentrismo, enquanto movimentos imanentes de superação do presente em direções emancipatórias. Vimos que a teoria crítica conjuga perspectiva, contraposição e desvelamento. Cabe agora retornar aos três termos à luz do excurso feito até aqui. O primeiro termo implica que a crítica social se enraíza em um ponto de vista até então silenciado historicamente, uma vivência e uma perspectiva sobre a realidade que não estavam claramente enunciadas. O desenrolar da teoria, nesse sentido, tensiona a indiferença do conhecimento social à subjetividade de quem o move. Isso não significa absolutizar identidades em um sentido epistemológico. O caminho é menos o de como determinadas identidades individuais produzem perspectivas que fazem teoria, mas antes como determinadas viradas críticas só são inteligíveis historicamente a partir da emergência de um ponto de vista subalterno. 


\section{Pedro Borba}

Nesse sentido, a crítica ao eurocentrismo é inseparável das vozes dissonantes do resto do mundo contra o arcabouço europeu da história universal. Por trás da crítica de um intelectual como Said ou Fanon, formulada com o alcance e a profundidade que the são característicos, a construção de perspectiva envolve uma subjetividade coletiva mais ampla (Domingues, 1999). E a construção dessas perspectivas foi plural como não poderia deixar de ser: contra o universalismo europeu se insurgiram as perspectivas do colonizado, do Terceiro Mundo, da negritude na diáspora, da nação, da periferia, entre infindáveis enquadramentos possíveis. Em um ensaio genial, elaborado no contexto do cinquecentenário de 1492, Enrique Dussel propôs que a América Latina fosse pensada como a te-ixtli da modernidade, palavra em nauátl para o verso, a outra face, o lado coberto, o que remete a uma experiência vivida ao revés, do pandemônio da conquista e seu legado de desumanização, daquele horizonte de libertação pela razão que a modernidade significava na Europa renascentista (Dussel, 1992: 48-53).

O segundo termo, contraposição, se explica por não serem quaisquer pontos de vista a irromper, mas a perspectiva dos subalternos contra um determinado estado de coisas e suas racionalizações. A contraposição ao pensamento vigente busca, como disse Florestan Fernandes (1976: 10), "equacionar, sociologicamente, a negação de um presente indesejável". Com isso, há uma fratura posta no plano ético, no horizonte do que é bom, desejável, positivo (Santos, 1999: 199-200). O que é tido como bom e justo para a vida de uma mulher em uma ordem patriarcal não é "bom" nem "justo" para a crítica feminista dessa ordem; a busca por crescimento estável do capitalismo pelos economistas burgueses não pode ser um objetivo da crítica marxista da economia política. O desenvolvimento não pode ocupar o mesmo terreno de utopia em uma crítica ambientalista do extrativismo.

Da mesma forma, a crítica ao eurocentrismo se desenvolve em contraposição à reflexividade imperial da expansão europeia e suas derivações, o "colonialismo do progresso", o orientalismo, o racismo científico, a modernização, o colonialismo interno. O campo da crítica é, nesse sentido, a reflexividade das lutas anti-imperialistas ao redor do mundo, de modo a constituir um horizonte histórico de autodeterminação. Com efeito, é uma doutrina recente o preceito de que os povos oprimidos, independente de quaisquer atributos culturais ou raciais, têm o legítimo direito de rechaçar a tutela civilizadora de um estado mais poderoso em nome de um desenvolvimento autônomo (Wallerstein, 2006: 15-16).

Além de perspectiva e contraposição, a teoria crítica é fundamentalmente desvelamento de realidade, um impulso de conhecimento em terreno novo. Em um balanço dos avanços na teoria política, Terrence Ball sublinhou como "novas eras históricas abrem novos contextos de descoberta, especialmente conforme identidades e discursos previamente submersos emergem e começam a articular preocupações e perspectivas até então ocultas" (Ball, 2006: 08). Como ilustração do argumento, ele cita acadêmicos homossexuais como John Winckler e Michel Foucault. Para além de uma perspectiva particular, esses intelectuais reinventaram radicalmente a forma como tratamos temas como poder, sexualidade, normalidade e desvio, vigilância e controle. Descobertas feitas em contraposição a uma sabedoria convencional possibilitam não só novas ideias, mas sobretudo novas indagações que extrapolam em muito seu contexto original de formulação.

Nesse aspecto, não deveria restar dúvida de que a crítica de Edward Said aos Estudos Orientais nos desvelou novas formas de associação entre ciência e império, entre conhecimento, poder e alteridade. Da mesma forma, a leitura de Fanon sobre as expressões psicossociais do colonialismo fertilizou uma vasta gama de estudos sobre a constituição da subjetividade e das estruturas de dominação, bem como a vivência cotidiana do racismo. Esses desvelamentos possuem um poder transformativo. Eles reentram na realidade de onde vieram, encarnando a teoria crítica em prática política, em linguagem, em peças culturais. Mais do que 


\section{Pedro Borba}

isso, uma vez desveladas experiências periféricas e coloniais, e os inúmeros marcadores de alteridade que elas carregam, a própria narrativa axial da modernidade ocidental não consegue sustentar-se incólume (Bhambra, 2007). É nesse contexto que, após um século de declínio do imperialismo europeu no resto do mundo, sem que suas consequências tenham em absoluto desaparecido, é razoável perguntar-se qual até que ponto o universalismo eurocêntrico é, ou não, apenas mais uma arma de destruição em massa (Wallerstein, 2006).

\section{Provincializando a Europa: o anti-eurocentrismo como estratégia de pesquisa}

A ideia de que a Europa possa ser de alguma forma "provincializada" (c.f. Chakrabarty, 2000) no âmbito da teoria social se tornou um apelo tão sedutor quanto elusivo. Por um lado, tornou-se prática rotineira desqualificar toda teoria existente com base em suas premissas eurocêntricas, igualando Europa e modernidade a um bloco de racionalidade iluminista. Pós-modernismo e pós-colonialismo se aliam aqui em um esforço destituinte do campo. Frederick Cooper observou a ironia pela qual, nesse novo contexto, os europeus passam a ser praticamente um "povo sem história", já que sua historicidade é subsumida à metanarrativa da modernidade ocidental, uma caracterização indistinta de três ou quatro séculos (Cooper, 2005: 06). Em meio a esse novo senso comum anti-eurocêntrico, o historiador indiano Dipesh Chakrabarty (2000) definiu provocativamente um "paradoxo cotidiano das ciências sociais do Terceiro Mundo": embora as teorias produzidas na Europa não tomassem em nenhuma consideração as experiências dos povos colonizados ou periféricos, os estudiosos do Terceiro Mundo ainda assim encontravam utilidade para essas teorias para explicar sua própria realidade. Disso adviria a questão: "o que permitiu aos sábios europeus ocidentais desenvolver tamanha clarividência com relação a sociedades das quais eles eram empiricamente ignorantes?" (Chakrabarty, 2000: 29).

O percurso feito até agora nesse artigo oferece algumas pistas. Obviamente, há ironia na questão: o que permitiu a dita clarividência dos sábios europeus foi um processo histórico pelo qual o resto do mundo teve sua história envergada radicalmente pela experiência colonial, a ponto de suas sociedades se prestarem à análise por categorias formuladas originalmente na Europa. Ou seja: tal paradoxo não existe porque Hobbes, Madison ou Rousseau dispussessem de um dom extraordinário de falar sobre sociedades que não conheceram, mas porque a sociedade que eles tentavam entender vivia um peculiar processo de extroversão violenta por meio do qual, hoje em dia, "estados soberanos", "democracias liberais" ou "soberania popular" se tornaram temas de interesse fora do perímetro em que aqueles intelectuais estavam preocupados em intervir.

Dessa forma, não é unicamente por um desvio de conduta eurocêntrico que esses "velhos homens brancos europeus" continuam reaparecendo em currículos, ementas e bibliografias. Há um processo histórico real que faz com que o tema hobbesiano não seja um típico particularismo inglês, assim como "O Capital" de Marx ou "O Príncipe" de Maquiavel dificilmente são lidos hoje como exemplo de tradições renana ou florentina de prosa social. 0 paradoxo das ciências sociais do Terceiro Mundo remonta, antes de tudo, à sua inserção subordinada em um mundo que integrou-se por força do imperialismo europeu. Esse processo confere as condições históricas de possibilidade do eurocentrismo como representação de mundo, como ideologia dominante (Amin, 1989).

Ele é igualmente responsável pela produção de desigualdades persistentes, que se reproduzem no campo acadêmico. Nesse sentido, não se pode escamotear o fundamento material da reprodução de centros e periferias na circulação mundial de conhecimento (Beigel, 2013). A decisão de descartar o pensamento eurocêntrico não fará desaparecer as assimetrias que o subsidiam no presente. É nesse sentido que não há como produzir análise social livre de 


\section{Pedro Borba}

ou sem eurocentrismo, mas fundamentalmente contra ele e para além dele. 0

anti-eurocentrismo como estratégia de pesquisa é uma crítica imanente a uma realidade desigual engendrada pelo colonialismo moderno. Abre, assim, um terreno reconstruir conceitualmente alternativas às "posições acadêmicas que privilegiam uma parte do mundo sem qualquer reconhecimento das vidas, mortes (e vidas mortas no caso da escravidão) que contribuíram para que aquela parte do mundo se tornasse privilegiada" (Bhambra, 2007: 146).

O horizonte atual de "provincializar a Europa" foi aberto pela erosão do poder europeu sobre o resto do mundo ao longo do século XX, e pelos movimentos por autodeterminação que efervesceram em seu bojo. Há uma diferença qualitativa, assim, com relação às condenações ao colonialismo no interior da reflexividade imperial europeia. Como sabemos pelo exemplo já citado de Michel de Montaigne, ou quiçá de Bartolomeu de las Casas antes e do abade Raynal depois dele, a Europa moderna não foi um monolito pró-imperialista nem mesmo quando seu poder estava no zênite. Ainda assim, o que hoje identificamos como crítica ao eurocentrismo não emerge do juízo sobre a virtude ou o vício embutido na colonização ultramarina, mas da prerrogativa desta de erigir sobre si uma história universal que tem o colonizador como demiurgo. Ao final do século XX, em oposição, o mundo mudara a ponto de tornar implausível, anacrônica, obsoleta a equiparação automática entre singularidade ocidental e civilização moderna que o pensamento eurocêntrico consagrara.

Nesse sentido, "provincializar" a Europa como estratégia de pesquisa carrega dois sentidos centrais, ligados aos desvelamentos abertos pela crítica ao eurocentrismo. O primeiro deles advém da descompactação entre a "modernidade" e as experiências das metrópoles imperiais, supondo que a primeira não se esgota nas últimas. Se as sociedades modernas não são variantes, com eventuais distorções, atrasos e localismos, do complexo institucional da Europa Ocidental, há de fato um campo vasto de pesquisa, não só para reinserir a heterogeneidade nas categorias teóricas usuais como "cidadania" ou "nacionalidade", mas para trazer a lume categorias possivelmente irredutíveis a elas.

Em um segundo sentido, a crítica ao eurocentrismo desvela conexões no desenvolvimento da modernidade, que permitem reavaliar ambos os pontos em contato. $A$ história da Revolução Haitiana hoje não só é inseparável da Revolução Francesa, mas atribui nova luz a seus debates doutrinários. Como disse Trouillot, "quanto mais os mercadores e mercenários europeus compravam e conquistavam outros homens e mulheres, mais os filósofos europeus escreviam e falavam sobre o Homem" (Trouillot, 1995: 75; ver também Mills, 1997; Sala-Molins, 2006). As conexões, no sentido defendido por Bhambra (2014), têm consequências conceituais. As noções de "direitos humanos", "soberania" ou de "estado de bem-estar social", por exemplo, não podem permanecer constantes se reavaliadas pelo prisma dos povos não-ocidentais, isto é, das conexões mundiais que lhe constituíram historicamente. A crítica ao eurocentrismo implica um desafio de reconstrução conceitual nas Ciências Sociais, já que denunciar o "provincianismo mascarado de universalismo é fundamental, mas igualmente importante é avançar para além da denúncia, rumo a uma teorização sistemática" (Bringel \& Domingues, 2015: 61). No entrecruzamento dos dois sentidos acima, essa reconstrução teórica não se resolve pela absorção de novos casos, expressões e sotaques a uma ciência pretensamente ecumênica, mas aponta, no presente, para a crítica e a superação das formas de desumanização e dominação que o colonialismo moderno arraigou historicamente. 


\section{Considerações finais}

Pedro Borba

Este artigo desenvolve um argumento panorâmico a respeito do significado do eurocentrismo e dos caminhos para sua superação. De saída, é imprudente reduzir o problema a uma disputa intramuros do mundo acadêmico, como se poderia inferir pelas manifestações típicas do eurocentrismo que listamos ao princípio (a deferência a um cânone intelectual restrito, a desigualdade na circulação do conhecimento, o falso universalismo das teorias ocidentais clássicas e a redução da modernidade à difusão institucional da Europa moderna). Constatamos que, embora reais e relevantes, essas manifestações remetem a um processo histórico mais amplo que as tornam inteligíveis no presente. Esse processo é o colonialismo moderno, um dos maiores fermentos para a imaginação social e política nos últimos cinco séculos.

Adotando essa linha, perseguimos a formação de uma representação hegemônica de mundo assentada na diferença colonial. Resumimos essa formação em três instâncias: primeiro, um poder de caráter negativo, que produz silenciamento e invisibilidade das sociedades autóctones; segundo, um vigoroso impulso criativo resultante da expansão imperial, que, ao referenciar todas as culturas, toda a história e todo o conhecimento ao próprio colonizador, faz com que este possa se projetar universal; e, terceiro, a reinserção da diferença cultural em uma chave temporalizada, traduzindo os demais povos em estágios precedentes do desenvolvimento histórico liderado pela Europa imperial. É com base nesse percurso que definimos o eurocentrismo como uma espécie de reflexividade imperial, que se tornou hegemônica nos séculos XVIII e XIX e desde então não foi de todo abandonada.

Ao apontar a crítica ao eurocentrismo como reflexividade das lutas anti-imperialistas ao redor do mundo, o objetivo foi ressaltar que, para além da originalidade das e dos intelectuais periféricos, suas condições de possibilidade foram postas por transformações históricas mundiais. A "revolução intelectual" do Terceiro Mundo no século XX foi inseparável, se vista panoramicamente, da aspiração por autodeterminação política. Nessa conjugação posicionamos o desenvolvimento de uma teoria crítica. Tomando uma conotação ampla para o termo, propomos pensá-la como um feixe entre perspectiva, contraposição e desvelamento. Ao deslocar o olhar para uma experiência periférica, usando-a como plataforma de confrontação a uma situação injusta e ao saber vigente que a naturaliza, é possível também revelar dimensões novas da realidade, reconhecê-las e incidir sobre elas. É importante, diante disso, reconhecer a interdependência entre os termos: o desvelamento, se feito um objetivo isolado, redunda em positivismo, tratando o resto do mundo como um conjunto novo de casos para testar teorias; a contraposição, se um fim em si mesma, se converte em simples destituição conceitual, descartando qualquer abstração ou teoria como um retorno renitente ao universalismo imperial; por fim, a perspectiva subalterna, enquanto dimensão crítica por si só, tende a reificar identidades, experiências e discursos. Buscamos demonstrar que o potencial do entrelaçamento entre os três movimentos se revela menos em um intelectual ou obra isolados, mas sobretudo na constituição das subjetividades coletivas que os forjam em "aspirações de uma época". A "revolução intelectual" do Terceiro Mundo é uma espécie de bloco histórico anti-eurocêntrico, cujos desdobramentos ainda estamos tentando discernir.

Por fim, o desafio contemporâneo de "provincializar a Europa" nas Ciências Sociais permanece em aberto, mas parece impossível superá-lo sem aprofundar a reconstrução conceitual desde as margens. Contra o rastro de silenciamento imposto pela conquista, há que se resgatar as trajetórias e experiências alternativas no mundo moderno, reforçando o poder das conexões recíprocas, mesmo que assimétricas, entre suas partes. Contra a temporalização da diferença em uma narrativa universalista, estamos muito mais inclinados a perceber a heterogeneidade da textura do tempo histórico (Chakrabarty, 2000: 27-71; Chatterjee, 2011: 129-153). No limite, o desenvolvimento da teoria crítica como sucessivos movimentos 
anti-eurocêntricos permite retrucar ao paradoxo levantado por Chakrabarty (2000) com uma forma de "paradoxo cotidiano das Ciências Sociais do Primeiro Mundo" nos seguintes termos: como é possível continuar chamando de teoria geral aquilo que ignora ou distorce a experiência social da maior parte do mundo?

(Recebido para publicação em setembro de 2020)

(Reapresentado em setembro de 2020)

(Aprovado para publicação em outubro de 2020)

\section{Cite este artigo}

BORBA, Pedro, 2020. Para uma teoria crítica do eurocentrismo: história, colonialismo e o resto do mundo. Revista Estudos Políticos: a publicação semestral do Laboratório de Estudos Hum(e)anos (UFF). Rio de Janeiro, Vol.11 | N.1, pp.63-82, outubro de 2020.

\section{Notas}

1. Diferença colonial designa a essencialização dos povos colonizados como diferentes com relação ao parâmetro dos colonizadores, estes últimos correspondendo ao ser humano no sentido completo de suas faculdades individuais e coletivas. Embora as formas históricas pelas quais essa essencialização opera sejam variadas e contingentes, é possível considerar que a diferença colonial naturaliza a dominação ao incutir na diferença um sentido de inferioridade ou imaturidade.

2. Como frequentemente ocorre, o uso de "europeu" aqui tem um sentido figurado em que designa os centros históricos de poder mundial na Europa Ocidental e nos Estados Unidos, o que, em outros contextos, é abrigado pelas expressões "norte global" ou Ocidente.

\section{Referências bibliográficas}

ABU LUGHOD, Janet (1989). Before European hegemony: the world-system AD 1250-1350. Nova Iorque/Oxford: Oxford University Press.

ADAS, Michael (1990). Machines as measure of men: science, technology, and ideologies of Western dominance. Ithaca/London: Cornell University Press.

AMIN, Samir (1989. Eurocentrismo: crítica de una ideología. México: Siglo XXI.

BALL, Terrence (2006). Must political theory be historical? Contributions, n. 2, vol. 1, pp. 07-18. 
PARA UMA TEORIA CRÍTICA DO EUROCENTRISMO: HISTÓRIA, COLONIALISMO E O RESTO DO MUNDO

Pedro Borba

BEIGEL, Fernanda (2013). Centros y periferias en la circulación internacional del conocimiento. Nueva Sociedad, n. 245 , pp. $110-123$.

BHAMBRA, Gurminder (2014). Connected sociologies. London/New York: Bloomsbury Academic.

BHAMBRA, Gurminder (2007). Rethinking modernity: postcolonialism and the sociological imagination. Basingstoke/Nova Iorque: Palgrave Macmillan.

BLAUT, James (1993). The colonizer's model of the world: geographical diffusionism and Eurocentric history. Nova York: The Guilford Press.

BRINGEL, Breno \& DOMINGUES, José Maurício (2015). Teoria social, extroversão e autonomia: impasses e horizontes da sociologia (semi)periférica contemporânea. Cadernos CRH, vol. 28, n. 73, pp. 59-76.

CÉSAIRE, Aimé (1978). Discurso sobre o colonialismo. Lisboa: Sá da Costa Editora.

CHAKRABARTY, Dipesh (2000). Provincializing Europe: post-colonial thought and historical difference. Princeton: Princeton University Press.

CHANDRA, Uday (2013). The case for a postcolonial approach to the study of politics. New Political Science, n. 35, vol. 3, pp. 479-491.

CHATTERJEE, Partha (2011). Lineages of political society: studies in postcolonial democracy. Nova York: Columbia University Press.

CHATTERJEE, Partha (1993). The nation and its fragments: colonial and postcolonial histories. Princeton: Princeton University Press, 1993.

COMAROFF, Jean \& COMAROFF, John (2013). Teoría desde el sur: o cómo los paises centrales evolucionan hacia África. Buenos Aires: Siglo Ventiuno Editores.

CONNELL, Raewyn (2012). A iminente revolução na teoria social. Revista Brasileira de Ciências Sociais, vol. 27, n. 80, pp. 9-20.

COOPER, Frederick (2005). Colonialism in question: theory, knowledge, history. Berkeley/Los Angeles: University of California Press.

DOMINGUES, José Maurício (2011). Vicissitudes e possibilidades da teoria crítica hoje. Sociologia \& Antropologia, vol. 1, n. 1, 71-89.

DOMINGUES, José Maurício (1999). Criatividade social, subjetividade coletiva e a modernidade brasileira contemporânea. Rio de Janeiro: Contracapa. 
Pedro Borba

DUSSEL, Enrique (1992). 1492, el encubrimiento del otro: hacia el mito de la modernidad. La Paz: UMSA/Plural Editores.

FEDERICI, Silvia (2004). Calibã e a bruxa: mulheres, corpo e acumulação primitiva. Coletivo Sycorax. Consultado online: http://coletivosycorax.org/livros-traduzidos/. Último acesso em 06/02/2019.

FERNANDES, Florestan (1976). A revolução burguesa no Brasil. Rio de Janeiro: Zahar Editores.

FRASER, Nancy (1985). What is critical about critical theory? The case for Habermas and gender. New German Critique, N. 35 (Special Issue on Jurgen Habermas), pp. 97-131.

FUNES, Patricia (2006). Salvar la nación: intelectuales, cultura y política en los años veinte latinoamericanos. Buenos Aires: Prometeo Libros.

HALL, Stuart (1995). "The West and the rest: discourse and power". Em HALL, Stuart \& GIEBEN, Bram (orgs.) Formations of modernity. Cambridge: Polity Press, pp. 275-332.

JASMIN, Marcelo (2011). "As armadilhas da história universal". Em NOVAES, Adauto (org.). Mutações: a invenção das crenças. São Paulo: SESC-SP, pp. 377-403.

KARL, Rebecca (1998). Creating Asia: China in the world at the beginning of the twentieth century. The American Historical Review, vol. 103, no. 4, pp. 1096-1118.

KNÖBL, Wolfgang (2015). Reconfigurações da teoria social após a hegemonia ocidental. Revista Brasileira de Ciências Sociais, vol. 30, n. 87, pp. 5-17.

LANDA, Diego de (1959 [1566]). Relacion de las cosas de Yucatán. México: Porrúa Editorial, .

LANDER, Edgardo (org.) (2005) A colonialidade do saber: eurocentrismo e ciências sociais. Perspectivas latino-americanas. Buenos Aires: CLACSO.

LECHNER, Norbert (2012). Obras completas: estado y derecho (vol. 1). México: Fondo de Cultura Económica/FLACSO México.

LOCKE, John (1994 [1689]). Segundo tratado sobre o governo civil; ensaio sobre a origem, os limites e os fins verdadeiros do governo civil. Petrópolis: Vozes.

MEEK, Ronald (1976). Social Science and the ignoble savage. New York: Cambridge University Press.

MILLS, Charles (1997). The racial contract. Ithaca: Cornell University Press. 
PARA UMA TEORIA CRÍTICA DO EUROCENTRISMO: HISTÓRIA, COLONIALISMO E O RESTO DO MUNDO

Pedro Borba

MONTAIGNE, Michel de (1972 [1588]). Ensaios. São Paulo: Abril (Coleção Os Pensadores).

PAGDEN, Anthony (1986). The fall of natural man: the American Indian and the origins of comparative ethnology. Cambridge: Cambridge University Press.

POULANTZAS, Nicos (1979). Estado, poder y socialismo. Madrid: Siglo XXI.

QUIJADA, Mónica (2003). ¿Qué nación? Dinámicas y dicotomías en el imaginario hispanoamericano. Em ANNINO, Antonio \& XAVIER-GUERRA, François (orgs). Inventando la nación: Iberoamérica siglo XIX. México: Fondo de Cultura Económica, pp. 287-315.

QUIJANO, Aníbal (2000). "Coloniality of power and eurocentrism in Latin America". International Sociology, vol. 15 , n. 2, pp. 215-232.

SALA-MOLINS, Louis (2006). The dark side of the light: slavery and the French Enlightenment. Minneapolis/London: Minnesota University Press.

SAID, Edward (2008). Orientalismo. Barcelona: Random House Mondatori.

SANTOS, Boaventura de Sousa (1999). "Por que é tão difícil fazer teoria crítica?". Revista Crítica de Ciências Sociais, n.54, pp. 194-216.

SELASSIE, Haile (2011 [1936]). Adress to the League of Nations. Em BLAISDELL, Bob (org.). Great speeches of twentieth century. Nova York: Dover Publisher, pp. 46-54.

TODOROV, Tzvetan (1982). 1492: a questão do outro. São Paulo: Martins Fontes.

TROUILLOT, Michel-Rolph (1995). Silencing the past: power and the production of history. Boston: Beacon Press.

WALLERSTEIN, Immanuel (2006). European universalism: rhetoric of power. Nova York: The New Press.

WALLERSTEIN, Immanuel (1997). "Eurocentrism and its avatars: the dilemmas of Social Science". Sociological Bulletin, vol. 46, no. 1, pp. 21-39. 